\title{
THE EFFECTIVENESS OF USING KAHOOT AS A MEDIA IN TEACHING READING
}

\author{
Ima Chusnul Chotimah ; Muhammad Farhan Rafi \\ Imachus.stkipjb@gmail.com; m.farhan@stkipjb.ac.id \\ STKIP PGRI, Jombang
}

\begin{abstract}
This research focuses on the use of Kahoot as a media in teching reading for the English Departement students of STKIP PGRI Jombang in academic year 2017/2018. The method used is experimental research with quasi experimental design. There are two classes, they are $2016 \mathrm{~B}$ as the experimental class and $2016 \mathrm{~A}$ as the control class. The teaching process done in experimental class was using Kahoot as a media, while in 2016 A was using textbook as a media. The instrument used was a test. Before giving the test, the researchers did the content validity and construct validity by conducting the tryout to know the validity and reliability criteria of the test. After knowing all of them are valid and reliable, giving pre test, treatment, and post test was done to get the data of the research. After that, the researchers analyzed the data by using ANCOVA. The result shows that the significant value is 0.02 , it is lower than the significant level 0.05. It means that the use of Kahoot as a media for the English Department students of STKIP PGRI Jombang influences their reading skill.
\end{abstract}

Keywords: Kahoot, Media, Teaching Reading

\section{INTRODUCTION}

English as a compulsory subject delivers its skills into four categories: listening, speaking, reading and writing. To improve these English language skills, students must be proficient on the each area, including reading comprehension. In the university environment, the most important component of English proficiency is English reading comprehension, especially in an academic field (Ching \& Hui, 2013; Huckin, Haynes, \& Coady, 1993). Thus, to improve students' ability in understanding reading, teachers should apply appropriate media that can enhance the students' ability.

Media is the plural of medium, which in learning and training environments, is the means of communicating and transferring a learning concept or objective to another individual. Media are the replicable "means", forms, or vehicles by which instruction is formatted, stored, and delivered to the learner (Schwen, 1977). According to Oswalt (2010) there are four types of media, such as: (1) Print Media, is used to describe the traditional or "oldfashioned" print-based media that today's parents grew up with, including newspapers, magazines, books, and comics or graphic novels. (2) Television, it has been entertaining American families for over fifty years. In the beginning, there were few programs to pick from, but today, there are literally hundreds of general and specialty channels to choose from and thousands upon thousands of programs. (3) Movies or films, are the oldest form of motion picture technology capable of capturing lifelike video-style images. Originally, movies could only be consumed at a neighborhood movie theater, but these days movies are widely available for people to consume in their homes, on their computers, and even in through their telephones. (4)Video games, it is available since the early 1980s, video games have only grown in popularity among youth. Today's games make use of advanced graphics and processors to enable three dimensional game play featuring highly realistic landscapes and physics simulations, and the ability to 
compete against other players through a network connection. Modern video games are immersive, exciting and increasingly interactive. Players feel like they really are in the situation because of the life-like graphics and sounds.

One of the main function of the media is teaching as a tool to help teach that also influence the climate, conditions, and the learning environment is created and styled by the teachers. Arsyad Azhar (2005, p.1516) explains that the use of teaching media in the orientation phase of teaching will help the learning process and effectiveness of delivery and content of the subjects at the time, as it also raised the motivation, students' interests and also help students increase understanding, to present the data with interesting and reliable, ease of data, and compress information.

Meanwhile, Dayton and Kemp (1985) in Arsyad Azhar (2005, p. 22) revealed some results of research that shows the positive impact of using media as a primary teaching directly as follows: (1) delivery of lesson to be more basic, (2) Teaching can be more interesting, (3) learning to become more active, (4) Teaching time that is required can be shortened, (5) The quality of students learning can be improved, (6) Learning can be given where and whenever desired or needed, (7) Positive attitude toward students what they learned and the process of learning can be improved, (8) the role of teachers can be changed to a more positive direction.

From the theory above, the researchers are interested to apply one type of media that related to video games, but it has been combined by modern online game namely kahoot. It based on two previous studies; First, the study was done by Nurul Nisa Omar (2017) KDU University College, Selangor Malaysia. The study talks about The Effectiveness of Kahoot Application toward students' good feedback practice. From the results of the focus group discussion, Kahoot application is only able to fulfill four of the seven principles of good feedback practice. In parallel, Strommen (1992) states that technology assessment is difficult to merge the seriousness of a test within the fun engaging interactive test. For future implication, the enhancement of technology-based assessment such as Kahoot application can be improved by focusing on students' dialogue with lecturers, clearer objectives, and quality of information delivered in the test. Second, the study done by Budiati from Ngudi Waluyo University. The study talks about ICT (Information and Communication Technology) Use : Kahoot Program for English Students' Learning Booster. The result shows that after using Kahoot for teaching, the students are very interested in joining the class; they are more eager in coming to the class, they pay more attention in English and they were interested in learning more about what they had learn and want to tell others about it.

Both previous studies above focuse on how is the students response after using Kahoot in teaching and learning. The positive response comes from both previous study are the students have fun to do this activity and it can boost their learning. But for the other result from the study done by Nurul Nisa Omar (2017), there are 3 good feed back practice do not arrise yet as stated in the study that do not have positive response from the students, e.g.: "although some did well in the Kahoot ranking, does not mean they will do well in final exam" (p3). It means there is a problem should be solved from the negative response. Answering well the questions from kahoot does not mean they will do well in final exam. From the background stated above, the researchers would like to solve the problem stated above by conducting the research The Effectiveness of Using Kahoot as a Media in Teaching Reading. 


\section{Teaching Reading}

Harmer (2003, p.68) stated that the following reason why getting students to read English text is an important part of teacher's job. Many of them want to be ble to read texts in English either for their careers, for study purposes or simply for pleasure. So, as a teacher should know the condition of the learners, what they need and what kind of material that suitable with them.

Dealing with the teaching of reading, Harmer (2003, p.70) added some principles behind the teaching of reading, they are: (1) Reading is not passive skill, (2) Students need to be enganged with what they are reading, (3) Students should be encouraged to respond to the content of reading text, not only to the language, (4) Prediction is a major of reading, (5) Match the task to the topic,(6) Good teachers exploit reading texts to the full. As a good teacher, we have to pay attention to those principles to do teaching and learning process specially in teaching reading.

\section{Types of Reading}

According to Brown (2003, p. 189), there are four types of reading: (1) Perceptive, it involves attending to the component of larger streches of discourse; letters, words, punctuation, and other graphemic symbol. (2) Selective, it is largerly an artifact of assessment format. In order to ascertain ones reading recognition of lexical, grammatical, or discourse features of language within a very short strench of language, certain typical tasks are used; picture cued task, matching, true or false, multiple choice, etc. (3) Interactive, it is stretches of language of several paragraphs to one page which the reader must, in psycholinguistic sense, interact with the text. (4) Extensive, it is as longer stretches of discourse, such as long articles and books that are usually read outside a classroom hour.

\section{Reading Assessment}

Brown (2003, p. 201) stated that there are seven kinds of reading assessment, they are: (1) Cloze task, in written language, a sentence with a word left out should have enough contexts that the reader can close that gap with a calculated guess, using linguistic expectancies, background experience and some strategic competence. (2) Impromptu reading plus comprehension questions, the reader reads a passage and answer some questions based on the passage. (3) Short answer task, a reading passage is presented and the test-taker reads questions that must be answered in a sentence or two. (4) Editing or longer texts, the test-taker has to detect a list of unrelated sentences that presented with an error. (5) Scanning, it is carried out by presenting test-taker with a text and requiring rapid identification of relevant bits of information. (6) Ordering Task, the test taker receives little strips of paper, each with a sentence on it, and assembling them into a story. (7) Information transfer; reading chart, maps, graphs and diagrams. The test-tker must be able to comprehend charts, maps, graphs, calendar, diagram, and the like.

\section{Media and the Benefits in Education}

Media is the plural of medium, which in learning and training environments, is the means of communicating and transferring a learning concept or objective to another individual. Media are the replicable "means", forms, or vehicles by which instruction is formatted, stored, and delivered to the learner (Schwen, 1977). According to John Naisbit, there are ten benefits of media in education, they are: (1) meets the needs of students to be wise consumers of media, managers of information and responsible producers of their ideas using the powerful multimedia tools of a global media culture. (2) Engages students bringing the world of media into the classroom connect learning with "real life" and validates their media 
culture as a rich environment for learning. (3) Gives students and teachers alike a common approach to critical thinking that, when internalized, becomes second nature for life. (4) Provides an opportunity for integrating all subject areas and creating a common vocabulary that applies across all disciplines. (5) Helps meet state standards while, at the same time using fresh contemporary media content which students love. (6) Increases the ability and proficiency of students to communicate (express) and disseminate their thoughts and ideas in a wide (and growing) range of print and electronic media forms - and even international venues.(7)Media literacy's "inquiry process" transforms teaching and frees the teacher to learn along with students -- becoming a "guide on the side" rather than a "sage on the stage." (8) By focusing on process skills rather than content knowledge, students gain the ability to analyze any message in any media and thus are empowered for living all their lives in a media-saturated culture. (9).By using a replicable model for implementation, such as CML's MediaLit $\mathrm{Kit}^{\mathrm{TM}}$ with its Five Key Questions, media literacy avoids becoming a "fad" and, instead, becomes sustainable over time because students are able to build a platform with a consistent framework that goes with them from school to school, grade to grade, teacher to teacher and class to class. With repetition and reinforcement over time, students are able to internalize a checklist of skills for effectively negotiating the global media culture in which they will live all of their lives. (10) Not only benefits individual students but benefits society by providing tools and methods that encourage respectful discourse that leads to mutual understanding and builds the citizenship skills needed to participate in and contribute to the public debate.

\section{When to Introduce the Media?}

According to some experts the time for introducing the media has special purpose, there are four times we can use to introduce the media, they are: (1) Before learning the concept. Showing media before the discussion gives students an image to which they can compare the topics under discussion. This approach allows quick reference to easily recalled examples. Schwartz and Bransford (1998) show that demonstrations focused on contrasting cases help students achieve expert-like differentiation. In addition, Schwartz and Martin (2004) found that carefully-prepared demonstrations "help students generate the types of knowledge that are likely to help them learn" from subsequent lectures.(2) After a brief introduction but before learning the concept. This method provides students with a brief capsule of what the media is about and what to look for -- helping to focus attention while watching the media. (3) After learning the concept. Showing media after describing a theory or concept allows the instructor to use the scenes as a case study. This approach helps students develop their analytical skills in applying what they are learning. (4) Before and after. Repeating the media is especially helpful when trying to develop student understanding of complex topics. Utilize the media before the discussion to give students an anchor. Guide students through a description or discussion of the topics. Rerun the media as a case study and ask students to analyze what they see using the theories and concepts just discussed. Also punctuate the rerun with an active discussion by asking students to call out the concepts they see in the scenes. This method helps to reinforce what they have just learned.

\section{Kahoot}

A Kahoot is a collection of questions on specific topics. Created by teachers, students, business-people and social users, they are asked in real-time, to an unlimited number of "players", creating a social, fun and game-like learning 
environment. Currently, there are 3 types of Kahoot:

1. Quiz

This is the most common type of Kahoot, epitomising our game-based approach to blended learning. There is no limit to the number of questions in a quiz. Each question can have an associated picture or video, and $2-4$ multiple choice answers. There must be at least one correct answer (but more can be chosen), and the timelimit for each question can be individually set from 5 seconds to 2 minutes. Aside from being a great way to engage and focus a whole room of people, quizzes can be used to formatively assess the knowledge of each individual in the room, and adapt their learning accordingly. They can be used to track progress of individuals over time, and inspire learners to enquire further by creating their own quizzes. Players answer questions displayed at the front of the room on their personal device, motivated to answer correctly and score the most points. The faster someone answers a question correctly, the more points they get. The top 5 highest points scorers are displayed on the leaderboard at the front in-between each question, and the ultimate winner is shown at the end. Results, including who answered what for each question, can be downloaded afterwards.

2. Discussion (previously 'Quick poll') Discussions are designed to do exactly what they say - facilitate a conversation. They are simply one quick question with no right or wrong answer, which can have an associated picture or video and 2 - 4 alternative answers. They should be used to gather opinions on current affairs, divisive topics, or even ask "what shall we do today?". Once again, players answer the question on their personal device. There is still a time-limit to answer within, however no points are involved. The collective results of the question are displayed at the front, acting as the basis for the discussion.

3. Survey

There are no limits to the number of questions in a survey. Each question can have an associated picture or video, and 2 - 4 multiple choice answers - however there are no right or wrong answers. They are just like traditional surveys except questions are asked in real-time to those present who answer on their personal devices. The results of each question can be debated there-and-then, and all survey results can be downloaded at the end.

\section{METHOD}

In this research, the researchers used the experimental research to measure the use of Kahoot as a media in teaching reading. The design is quasi experimental. It is the design that is not possible to the researcher selects the sample randomly different treatment to two different classes. (Latief, 2011, p. 95)

\section{Respondents}

The respondents are the English Department students of STKIP PGRI Jombang in academic year 2017/2018. There are two classes, 2016 A which has 38 students was the control group and 2016 B which has 39 students was the experimental group. The use of Kahoot as a media was done in experimental group, and the use of textbook was done in control group.

\section{Instruments}

The instrument used is a test. There are two kinds of test used in this research. First is multiple choice test which consists of 10 items, It was used for the exercises in the class. Second is essay test which consists of 4 items, it was used for pre test and posttest. It was refered to the indicators included: knowing and 
understanding main idea in genre (text types) and its rhetorics, emphasizing the use of appropriate reading strategies (skimming and scanning) to understand implicit information, and identifying the organization and genre (text types). Before adminestering, the test has to be valid and reliable. Therefore, it is needed to be judged by the expert and conducted a try out to know its validity and reliability. The try out was conducted to the different subject in the same grade. In measuring the validity, the researcher computed both content and construct validity. The researcher conducted content validity by asserting the expert judgement to know the test was need to be reconstructed or not. While the construct validity was computed from the results of the try out. All off the tryout score were accumulated by the appropriate formula for correlation to know the test validity. The researcher correlated the score by calculating
Pearson's Product Momemt. To perform the correlation in SPSS by choosing ANALYZE > CORRELATE > BIVARIATE (Larson, 2010, p. 163). While, in measuring the reliability, the researchers used Cronbach's alpha. To perform a correlation, choose ANALYZE $>$ SCALE > RELIABILITY ANALYSIS. Put all the items which contain judges' ratings of the participants in the "Items" box. Then, open the STATISTICS button and tick the "Interclass correlation coefficient" box. In the first drop-down menu choose TWO-WAY RANDOM, but leave the other drop-down menu alone. Also tick "Scale", "Item", and "Correlation". And the result of Cronbach's alpha is in the output (Larson, 2010, p.17). The output of validity and reliability of the instrument for both pretest and posttest are in the following tables:

Table 1. The Validity of Pretest

\begin{tabular}{|c|c|c|c|c|c|c|}
\hline \multicolumn{7}{|c|}{ Correlations } \\
\hline & & Item_1 & Item_2 & Item_3 & Item_4 & Total_Score \\
\hline \multirow[t]{3}{*}{ Item_1 } & Pearson Correlation & 1 & $.412^{*}$ & .093 & $.428^{*}$ & $.677^{\text {*** }}$ \\
\hline & Sig. (2-tailed) & & .026 & .633 & .020 & .000 \\
\hline & $\mathrm{N}$ & 29 & 29 & 29 & 29 & 29 \\
\hline \multirow[t]{3}{*}{ Item_2 } & Pearson Correlation & $.412^{*}$ & 1 & $.408^{*}$ & .182 & $.695^{* *}$ \\
\hline & Sig. (2-tailed) & .026 & & .028 & .346 & .000 \\
\hline & $\mathrm{N}$ & 29 & 29 & 29 & 29 & 29 \\
\hline \multirow[t]{3}{*}{ Item_3 } & Pearson Correlation & .093 & $.408^{*}$ & 1 & $.538^{* *}$ & $.711^{* * *}$ \\
\hline & Sig. (2-tailed) & .633 & .028 & & .003 & .000 \\
\hline & $\mathrm{N}$ & 29 & 29 & 29 & 29 & 29 \\
\hline \multirow[t]{3}{*}{ Item_4 } & Pearson Correlation & $.428^{*}$ & .182 & $.538^{* *}$ & 1 & $.766^{* *}$ \\
\hline & Sig. (2-tailed) & .020 & .346 & .003 & & .000 \\
\hline & $\mathrm{N}$ & 29 & 29 & 29 & 29 & 29 \\
\hline \multirow[t]{3}{*}{ Total_Score } & Pearson Correlation & $.677^{* *}$ & $.695^{* * *}$ & $.711^{* * *}$ & $.766^{* * *}$ & 1 \\
\hline & Sig. (2-tailed) & .000 & .000 & .000 & .000 & \\
\hline & $\mathrm{N}$ & 29 & 29 & 29 & 29 & 29 \\
\hline
\end{tabular}

Based on the description above, it was known that all the test items of pretest were significant at the 0.01 level. It means the items are valid, so the researchers are able to use the test in asserting the students' scores of pre-test without any reconstruction. 
p-ISSN: 2085-1383; e-ISSN: 2621-4156

\begin{tabular}{|c|c|c|c|c|c|c|}
\hline \multicolumn{7}{|c|}{ Correlations } \\
\hline & & Item_1 & Item_2 & Item_3 & Item_4 & Total_score \\
\hline \multirow[t]{3}{*}{ Item_1 } & Pearson Correlation & 1 & $.743^{* *}$ & $.789^{* *}$ & $.748^{* * *}$ & $.911^{\star \pi}$ \\
\hline & Sig. (2-tailed) & & .000 & .000 & .000 & .000 \\
\hline & $\mathrm{N}$ & 30 & 30 & 30 & 30 & 30 \\
\hline \multirow[t]{3}{*}{ Item_2 } & Pearson Correlation & $.743^{* *}$ & 1 & $.757^{* *}$ & $.748^{* *}$ & $.887^{\star \pi}$ \\
\hline & Sig. (2-tailed) & .000 & & .000 & .000 & .000 \\
\hline & $\mathrm{N}$ & 30 & 30 & 30 & 30 & 30 \\
\hline \multirow[t]{3}{*}{ Item_3 } & Pearson Correlation & $.789^{* *}$ & $.757^{* *}$ & 1 & $.763^{* *}$ & $.915^{\kappa \pi}$ \\
\hline & Sig. (2-tailed) & .000 & .000 & & .000 & .000 \\
\hline & $\mathrm{N}$ & 30 & 30 & 30 & 30 & 30 \\
\hline \multirow[t]{3}{*}{ Item_4 } & Pearson Correlation & $.748^{* *}$ & $.748^{* *}$ & $.763^{* *}$ & 1 & $.905^{\star \pi}$ \\
\hline & Sig. (2-tailed) & .000 & .000 & .000 & & .000 \\
\hline & $\mathrm{N}$ & 30 & 30 & 30 & 30 & 30 \\
\hline \multirow[t]{3}{*}{ Total_score } & Pearson Correlation & $.911^{* *}$ & $.887^{* *}$ & $.915^{* *}$ & $.905^{* *}$ & 1 \\
\hline & Sig. (2-tailed) & .000 & .000 & .000 & .000 & \\
\hline & $\mathrm{N}$ & 30 & 30 & 30 & 30 & 30 \\
\hline
\end{tabular}

**. Correlation is significant at the 0.01 level (2-tailed).

Based on the description above, it was known that all the test items of post-test were significant at the 0.01 level. It means the items are valid, so the researchers are able to use the test in asserting the students scores of post-test without any reconstruction.

Table 3. The Criteria of Reliability Coefficient

\begin{tabular}{cc}
\hline $0,80-1,00$ & Very high \\
$0,60-0,80$ & High \\
$0,40-0,60$ & Enough \\
$0,20-0,40$ & Low \\
$0,00-0,20$ & Very low \\
\hline
\end{tabular}

The criteria above mean that the test would be reliable in the range of enough to very high criteria. The researchers analyzed the reliability test by using Cronbach's Alpha for both pretest and posttest. And the result and interpretation of the data are described in the following tables:

Table4. The Realiability of PreTest

\begin{tabular}{rr}
\hline \multicolumn{2}{c}{ Reliability Statistics } \\
\hline Cronbach's Alpha & N of Items \\
.677 & 4 \\
\hline
\end{tabular}

Based on the table of criteria of reliability coefficient and reliability statistics of Cronbach's Alpha for pre-test above, it was found 0.677 . The test had high reliability, it was meant the test was constant in measuring with different participant, place, time and condition.

Table5. The Realiability of Post test

\begin{tabular}{rr}
\multicolumn{2}{c}{ Reliability Statistics } \\
\hline Cronbach's Alpha & N of Items \\
.923 & 4 \\
\hline
\end{tabular}

Based on the table of criteria of reliability coefficient and reliability statistics of Cronbach's Alpha for post-test above, it was found 0.923 . The test had very high reliability, it was meant the test was constant in measuring with different participant, place, time and condition.

\section{Procedures}

After doing the try out and knowing the result of the instrument are valid and reliable, the researchers did the following steps:

\section{Pre Test}

In this step, the researchers gave pre test for both experimental and control group. It aims to know the prior knowledge of the students before giving a treatment. The questions given were in the form of essay 
which has 4 items. The result of pre test was also used as covariate in analyzing the data.

\section{Treatment}

In this step, the researchers have three meetings of each class. In experimental group, the researchers used Kahoot as a media in teaching, while in control group, the researchers used textbook. The descriptions of the activity in the class are as follows:

Meeting 1. In this meeting, the students were given a material about exposition text. After uderstanding the material, the students were devided into several groups in which each group consists of 4 members. After that, distributed the text to each group, and then asked them to discuss it. For the following activity, the researchers asked to each group served their mobile phone, one group one mobile phone. Firstly, the researchers opened the kahoot system. Secondly, each group was asked to join by typing kahoot.it by giving their group names. Thirdly, each group should pay attention to 10 questions given and answer those questions through their mobile as fast as possible, because each item has limited time to answer. Each group should have a good team work to do this activity. because the last result was not shown from the true answer only, but also the fastest answer. In the end of this activity, they could know who is the winner of this activity.

Meeting 2. In the following meeting, the students were given different material, namely theuse scanning technique in reading. In this activity the students were given a text which has several questions. To answer those questions, it was related to scanning technique. The same activity has done as like in the previous meeting. Students were divided into several groups, discuss and understanding the text, then answer the questions through online game kahoot. In the second meeting, the students were more careful doing this activity because all of them wanted to get best result.

Meeting 3. The researchers did the same activity in the last meeting of the treatment. But the material focused on understanding the text using skimming technique. The similar activities have done to this group. Understanding the text by grouping and answering the questions through online game kahoot were done well by each groups.

While the experimental group focused on the use of Kahoot as the media in teaching process, textbook was used in control group in teaching process. To make it clear the differences of both media, here the teaching scenario used for both experimental group and control group:

Table 6. Teaching Scenario of Experimental Group and Control Group

\begin{tabular}{|c|c|}
\hline Experimental Group & Control Group \\
\hline Pre Teaching & Pre teaching \\
\hline $\begin{array}{l}\text { 1. Stimulate the students by giving several questions } \\
\text { related to the materials }\end{array}$ & 1. Ask them to read the material \\
\hline Whilst Teaching & Wilst Activity \\
\hline 1. Devide the students into several groups & 1. Ask several students to read the text \\
\hline Distribute the text to each group & Ask the students to translate the text together \\
\hline Ask the students to discuss and understand the text & Ask the students to answer the questions one by one \\
\hline Ask the students to join online game kahoot & \\
\hline $\begin{array}{l}\text { 5. Ask the students to answer the questions based on the } \\
\text { instruction given }\end{array}$ & $\begin{array}{l}\text { Post Teaching } \\
\text { 1. Make a conclusion }\end{array}$ \\
\hline 6. Discuss the result & \\
\hline \multicolumn{2}{|l|}{ Post teaching } \\
\hline 1. Giving feed back from the lecture & \\
\hline 2. Make a conclusion & \\
\hline
\end{tabular}




\section{Post Test}

In the last meeting, to maximize the research data the students were given a post-test which consist of 4 questions in the form of essay questions. The students did the post-test for about 90 minutes. They had to answer briefly based on the instruction given.

\section{Data analysis}

In data analysis, the researchers used ANCOVA to asserting the conclusion of the research. According to Pallant (2005, p.274) the procedure of using ANCOVA for analyzing the data are as follows: 1) from the menu at the top of the screen, click on Analyze, then select General Linear Model, then Univariate; 2) In the Dependent Variables box, put the dependent variable (students' achievement in post-test); 3 In the Fixed Factor box, put the independent variable (Media) ; 4) In the Covariate box, the covariate (students' achievement in pre-test); 5) Click on the Model button. Click on Full Factorial in the Specify Model section.
Click on Continue; 6) Click on the Options button; 7) In the top section labeled Estimated Marginal Means, click on your independent variable (Quick on the Draw Technique); 8) Click on the arrow to move it into the box labeled Display Means for. This will provide you with the mean score on your dependent variable for each group, adjusted for the influence of the covariate; 9) In the bottom section of the Options dialogue box, choose Descriptive statistics, Estimates of effect size and Homogeneity tests; 10) Click on Continue and then $O K$. Before anlyzing the data, the researchers input the data into data variable and data view to complete the analysis. Then, do the following steps based on the instruction above.

\section{FINDING AND DISCUSSION}

\section{Finding}

After computing the data by using ANCOVA, the researchers found that the significant value was lower than significant level $(0.02<0.05)$. It can be presented through the following table:

Table 7. The Result of Testing the Hypothesis

\begin{tabular}{|c|c|c|c|c|c|c|c|c|}
\hline \multicolumn{9}{|c|}{ Tests of Between-Subjects Effects } \\
\hline \multicolumn{9}{|c|}{ Dependent Variable:posttest } \\
\hline Source & $\begin{array}{l}\text { Type III Sum } \\
\text { of Squares }\end{array}$ & $\mathrm{df}$ & Mean Square & $\mathrm{F}$ & Sig. & $\begin{array}{c}\text { Partial Eta } \\
\text { Squared }\end{array}$ & $\begin{array}{l}\text { Noncent. } \\
\text { Parameter }\end{array}$ & $\begin{array}{l}\text { Observed } \\
\text { Power }^{\mathrm{b}}\end{array}$ \\
\hline Corrected Model & $1807.049^{\mathrm{a}}$ & 2 & 903.524 & 5.638 & .005 & .132 & 11.276 & .847 \\
\hline Intercept & 6897.657 & 1 & 6897.657 & 43.041 & .000 & .368 & 43.041 & 1.000 \\
\hline pretest & 49.488 & 1 & 49.488 & .309 & .580 & .004 & .309 & .085 \\
\hline Media & 1674.036 & 1 & 1674.036 & 10.446 & .002 & .124 & 10.446 & .891 \\
\hline Error & 11859.081 & 74 & 160.258 & & & & & \\
\hline Total & 311144.000 & 77 & & & & & & \\
\hline Corrected Total & 13666.130 & 76 & & & & & & \\
\hline
\end{tabular}

a. R Squared $=.132($ Adjusted R Squared $=.109)$

b. Computed using alpha $=.05$

Furthermore, Sahid Rahardjo (2015) stated that there are two ways in making decision of research hypothesis. The first way is done through comparing $\mathrm{F}$ value with $\mathrm{F}$ table. In this case, there are two requirements. First, when the $\mathrm{F}$ value is greater than $\mathrm{F}$ table, it means that the independent variable influences the dependent variable. In contrast, if the $\mathrm{F}$ value is lower than $\mathrm{F}$ table means that the independent variable does not influence the dependent variable. The second way can be done by concerning on the significance level. If the significance value is lower than 0.05 means that the independent variable influences the 
dependent variable. Afterward, if the significance value is greater than 0.05 means that the independent variable does not influence the dependent variable. In this research, the researchers used the second way to take the conclusion by comparing significant value with the significant level of the test. As a result the significant values was lower than significant level $(0.02<0.05)$. In final consideration, the researcher concluded that the independent variable named the use of Kahoot as a media in teaching reading influenced the dependent variable that was students' reading achievement. It means that the use of Kahoot as a media in teaching reading was exactly effective.

\section{Discussion}

Based on the theory mentioned in the previous chapter about the function of media, as stated by Dayton and Kemp (1985) in Arsyad Azhar (2005, p. 22) one of them said that the use of media in teaching process can improve and direct students' attention. It relates to the result of this research that the use of Kahoot is able to make the students more focus to the questions given. They must try to have full attention to answer the questions because they have limitation time to do it. They have a challenge to win the game by answering the questions well and having a shortest time. So thay, they must heve a full attention to do it. By having a good concentration, it can help them to understand the material well. The following theory said that the benefits of media such as; the teaching process are more interesting and interactive. It was streghtened by students antusias in doing that activity. They devided the job well, one of them focused on the operating the mobile, some of them focused on the questions and the text given and find the right answer. By deviding the job well, they can be interactive each other.

Based on the gap of research that develops from the previous study done by Nurul Nisa Omar (2017) a college student of KDU University Selangor Malaysia, in which the result of this research can answer the negative response from the students. The students who taught by using kahoot as a media perform better achievement than the students who taught by using textbook. In can be conclude that more practices in using kahoot in teaching and learning process can influence their reading achievement.

\section{CONCLUSION}

Based on the data analysis and the research result, it could be concluded that there was significant influence of the use of Kahoot as a Media in teaching reading for the English Department students of STKIP PGRI Jombang in academic year 2017/2018. It was based on the significance value was lower than the significance level $(0.02<0.05)$. From the research findings above, it could be stated that Ha was accepted. It means that the students taught by using Kahoot as a media had better reading achievement than the students taught by using textbook.

\section{ACKNOWLEDGEMENTS}

This research was supported by a research grant from Kementerian Riset, Teknologi and Pendidikan Tinggi Republik Indonesia in 2018.

\section{REFERENCES}

Angela Oswalt, MSW (2010). Types of Media. Retrieved June 13, 2018, from

https://www.mentalhelp.net/articles /types-of-media/

Arsyad Azhar (2005). Function and Benefits of Learning Media, 15-16. Retrieved June 13, 2018, from https://educationlearning.wordpress .com/2009/01/16/function-andbenefits-of-learning-media/

$\begin{array}{ccc}\text { Brown, } & \text { H.D. } & \text { (2003). Language } \\ \text { Assessment } & \text { Priciple } & \text { and } \\ \text { Classroom } & \text { Practice. } & \text { San } \\ \text { Fransisco: Pearson Education. } & \end{array}$

Budiati. (2017). ICT (Information and Communication Technology) Use: 
Kahoot Program for English Students' Learning Booster. The $1^{\text {st }}$ Education and Language International Conference (ELIC) Proceeding Center for International Language Development of Unissula, 178-188.

Harmer, Jeremy. (2003). How to Teach English. England: Person Longman.

Huckin, T. N., Haynes, M., \& Coady, J. (1993). Second Language Reading and Vocabulary Learning. New York, NY: Ablex Pub. Co.

Larson, Jenifer. (2010). A Guide to Doing Statistics in Second Language Research Using SPSS. New York: Routledge

Latif, Mohammad Adnan. 2011. Research Methods on Language Learning. Malang: UM PRESS

Omar, Nurul Nisa. (2017). The Effectiveness of Kahoot Application Towards Students' Good Feedback Practice. International Journal of Social Sciences, 3 (2), 2551-2562.

Pallant, Julie. (2005). SPSS Survival Manual: A Step by Step Guide to
Data Analysis Using SPSS for Windows (Version 12). Sydney: Allen \& Unwin.

Rahardjo, Sahid. 2015. Olah Data dengan SPSS available at http://spssindonesia.com. Retrieved September $22^{\text {nd, }} 2015$

Schwartz, Daniel L and John D. Bransford. (1998) "Time For Telling" Cognition \& Instruction, 16 (4): 475-523.

Schwartz, Daniel L. and Taylor Martin 2004. "Inventing to Prepare for Future Learning" Cognition and Instruction 22 (2): 129-184.

Schwen, T. 1977. Professional scholarship in educational settings: Criteria for inquiring. AV Communication Reviews, 25, 35-79. Retrieved June 13, 2018, from https://en.wikipedia.org/wiki/Medi a_(communication)

Strommen, E.F. (1992). The Future of Classroom Learning, 24 (4), 466476.

The Definition of Kahoot. Retrieved June 17, 2017, from http://blog.getkahoot.com/post/589 06886260/what-is-a-kahoot. 